\title{
ABO blood group polymorphism has an impact on prostate, kidney and bladder cancer in association with longevity
}

\author{
DONATAS STAKIŠAITIS ${ }^{1}$, MILDA JUKNEVIČIENE ${ }^{2}$, ALBERTAS ULYS $^{3}$, \\ DALIA ŽALIŪNIENË ${ }^{4}$, DAIVA STANISLOVAITIENE ${ }^{4}$, RAMUNE் ŠEPETIENË ${ }^{2}$, \\ ANŽELIKA SLAVINSKA ${ }^{5}$, KĘSTUTIS SUŽIEDÉLIS ${ }^{1}$ and VITA LESAUSKAITÉ ${ }^{6}$ \\ ${ }^{1}$ Laboratory of Molecular Oncology, National Cancer Institute, LT-08660 Vilnius; ${ }^{2}$ Department of \\ Histology and Embryology, Medical Academy, Lithuanian University of Health Sciences, LT-44307 Kaunas; \\ ${ }^{3}$ Oncosurgery Clinics, National Cancer Institute, LT-08660 Vilnius; ${ }^{4}$ Department of Ophtalmology, Medical Academy, \\ Lithuanian University of Health Sciences, LT-44307 Kaunas; ${ }^{5}$ National Blood Center, LT-10210 Vilnius; \\ ${ }^{6}$ Department of Geriatrics, Medical Academy, Lithuanian University of Health Sciences, LT-44307 Kaunas, Lithuania
}

Received December 4, 2017; Accepted April 16, 2018

DOI: $10.3892 / 01.2018 .8749$

\begin{abstract}
The aim of the present study was to assess the ABO blood group polymorphism association with prostate, bladder and kidney cancer, and longevity. The following data groups were analyzed: Prostate cancer $(n=2,200)$, bladder cancer $(n=1,530)$, renal cell cancer $(n=2,650)$, oldest-old $(n=166)$ and blood donors $(n=994)$ groups. The data on the ABO blood type frequency and odds ratio in prostate cancer patients revealed a significantly higher blood group $\mathrm{B}$ frequency $(\mathrm{P}<0.05)$; the pooled men and women, separate men bladder cancer risk was significantly associated with the blood group B $(\mathrm{P}<0.04)$; however, no such association was identified in the female patients. The blood group $\mathrm{O}$ was observed to have a significantly decreased risk of bladder cancer for females $(\mathrm{P}<0.05)$. No significance for the ABO blood group type in the studied kidney cancer patients was identified. A comparison of the oldest-old and blood donor groups revealed that blood group A was significantly more frequent and blood type B was significantly rarer in the oldest-olds $(\mathrm{P}<0.05)$. The results of the present study indicated that blood type B was associated with the risk of prostate and bladder cancer, and could be evaluated as a determinant in the negative assocation with longevity. Blood types $\mathrm{O}$ and $\mathrm{A}$ may be positive factors for increasing the oldest-old age likelihood. The clustering analysis by the ABO type frequency demonstrated that the oldest-olds comprised a separate cluster of the studied groups.
\end{abstract}

Correspondence to: Dr Donatas Stakišaitis, Laboratory of Molecular Oncology, National Cancer Institute, Santariškių 1, LT-08660 Vilnius, Lithuania

E-mail: dstakisaitis@yahoo.com

Key words: kidney cancer, prostate cancer, bladder cancer, longevity, ABO blood group

\section{Introduction}

The ABO blood group polymorphism has been associated with different diseases, cancer included (1). The cancer developments are variegated processes associated with aging. Protection from cancer and atherosclerosis is the main longevity reason. Long-survivors are an important group for the evaluation of genetic markers in cancer pathogenesis (2).

The 'histo-blood system' was first proposed for the ABO system characterized by the presence or absence of the carbohydrate antigens A and B on the erythrocyte membrane and blood plasma regular antibodies (anti-A, anti-B) (3). The A and B alleles encode a specific glycosyl-transferring enzyme. The blood groups are characterized by the presence of carbohydrate sugars on the red blood cell surface: $\mathrm{N}$-acetylgalactosamine for the A antigen and D-galactose for the $\mathrm{B}$ antigen, both for the blood type $\mathrm{AB}$ and neither for the phenotype $\mathrm{O}$. The $\mathrm{A}, \mathrm{B}$ and $\mathrm{AB}$-related carbohydrate sugars are situated on the $\mathrm{H}$ antigen, and the unmodified $\mathrm{H}$ antigen defines the blood group O (4). The A and B blood groups differ mainly by four amino acid substitutions (R176G, G235S, L266M, and G268A) from four common variants (rs7853989:C>G, rs8176743:G>A, rs8176746:C $>A$, and rs8176747:G>C), while the blood group $\mathrm{O}$ is characterized by a single nucleotide deletion (rs8176719(-;G)) which results in early protein termination $(5,6)$.

Population studies have demonstrated that the $\mathrm{ABO}$ group phenotypes frequencies vary widely from one ethnicity to another: The O blood group is common in South American and Africans natives, A and B being common in Asian and North European countries, respectively, while AB is more frequent in Korea, China and Japan (7).

The $\mathrm{ABO}(A B O, 9 \mathrm{q} 34.1)$ genes control the expression of part of the carbohydrates by the epithelial cells in the respiratory, genitourinary and gastrointestinal systems; the carbohydrate variability acts as a potential receptor for non-pathogenic and pathogenic microorganisms influencing immune responses $(8,9)$. 
The first report on the relation between the ABO blood group and cancer was published by England and Scotland researchers. A study of the frequency of the ABO blood groups in patients with stomack cancer indicated the A blood group to increase the risk, while the O blood type was protective (10). Thereafter, the correlation between the $\mathrm{ABO}$ blood type and other malignancies, such as gastric (11) and pancreatic (12-15), has been continuously reported. A total of 1.6 million healthy blood donors were followed in Denmark and Sweden: The A, B and AB blood groups were associated either with the increased or decreased risk of cancer at 13 anatomical sites as compared with the O blood group (16). Multiple mechanisms have been indicated to explain the blood type role in cancer progression, including altered immune response, inflammation and cellular adhesion (6,17-19).

The role of the specific genetic differences contributing to life expectancy is hardly known. Several genome sequencing and GWAS studies compared the total number of disease variants in centenarians and controls, indicating that there are some evidences that centenarians harbor the anti-aging polymorphisms which protect them from diseases, although long-survivors may show numerous disease variants at a rate similar to normal people, but they are protected from their effects $(20,21)$. The SNP (rs8176719) defining the most common allele responsible for the $\mathrm{O}$ blood group is related with longevity; the centenarians are more likely than controls to have the O blood group. In the GWAS analysis, this SNP has shown that the $\mathrm{O}$ blood group is associated with numerous protective effects (22). Genetic association studies identified that the polymorphism located near APOE was found to be consistently associated with extreme longevity (23). The longevity genetic markers in the Lithuanian population were found to be the low levels of apolipoprotein $\mathrm{B}(\mathrm{apoB})$ and the apoE and the low apoB/apoA-1 ratio $(24,25)$. The Gc1 allele of the vitamin D-binding protein demonstrated a marked decrease in the oldest-old cohort, and the Gc2 allele frequency is expressed in the opposite way in the Lithuanian population (26).

Long-survivors as the cohort are important for evaluating the role of genetic determinants in cancerogenesis and the related mortality. The further change in mortality patterns will increase success in reducing the number of cancer-related mortalities (27). In our study, we evaluated the ABO genetic variation in prostate, renal cell and bladder cancer patients, because the frequency of kidney and prostate cancer and mortality from these cancer types in the Lithuanian population is the higest in Europe $(28,29)$. The second task was to determine if the ABO blood type could be one of the multifactorial determinants in relation with the longevity as the resistance to cancer. The cluster analysis of the ABO blood group system in the Lithuanian population was selected to compare the structure of the analyzed data, their mathematical similarity and to form groups (clusters) in the population of Lithuania comparing the groups of prostate, kidney, bladder cancer patients with the healthy blood donors, long-survivors. The cluster method helps to estimate differences (similarities) and genetic distances among the groups of study subjects by showing the cluster hierarchy and their interconnectedness regarding the $\mathrm{ABO}$ group frequency. In the literature review, we included the $\mathrm{ABO}$ relationship with cancer, whereas resistance to cancerogenesis is an additional important determinant for longevity.

\section{Materials and methods}

The patient groups studied. The ABO blood group system has been identified in the following individual groups of the Lithuanian population: Control group (blood donors), long-lived individuals, individuals suffering from the prostate, bladder, kidney cancer. The study groups contained only the Caucasian population. The ethical approval of the study was obtained from Kaunas Regional Biomedical Research Ethics Committee (Kaunas, Lithuania; protocol no. BE-2-10; 2017); written informed consent was obtained from the patients. The blood donors group consisted of 994 individuals (aged 18 to 64 years) randomly selected from the National Blood Center. Individuals suffering from the urogenital system cancer were treated from 2005 to 2015 in the Department of Oncourology of the National Cancer Institute. Information about patients was collected from the information system database of the Department of Oncourology. As a control we also used data on the $\mathrm{ABO}$ blood group distribution from the oldest-old cohort individuals. As a function of age, the SNP allele frequency may not change in a monotonic fashion (30); alleles for some SNPs show a pattern such that 80 years old individuals have lower levels of alleles frequency, but young and very old people have similarly high allele frequencies (22). From twin studies, the survival heritability to the late eighties is estimated to be approximately $25-30 \%$ (31). In this case, our choice of the oldest-old cohort was accepted to be $\geq 80$ years as long-survivors are an important group for the evaluation of genetic markers in the tumorigenesis.

Data of the following groups of cancer patients are analyzed: Prostate cancer ( $\mathrm{n}=2,200$, men aged 40 to 93 years); bladder cancer $(n=1,530)$ : Men ( $n=1,201$, aged 21 to 98 years), women $(n=329$, aged 27 to 93 years); renal cell cancer $(n=2,650)$ : Men $(\mathrm{n}=1,553$, aged 19 to 89 years), women $(\mathrm{n}=1,097$, aged 19 to 90 years). The data criteria used for the selection of patients were as follows: Gender, blood group, age, date of the first diagnosis, disease codes (according to the International Classification of Diseases (ICD-10)). The group of oldest-old individuals consisted of 166 persons: Men aged 82 to 102 years $(n=54)$ and women aged 81 to 103 years $(n=112)$. For 48 long-lived individuals, the ABO blood group system phenotype was studied in patients undergoing cataract surgery (this subgroup was collected in the Eye Clinic of Kaunas Clinics of the Lithuanian University of Health Sciences Hospital), and others were collected as out-patients; the oldest-old individuals' selection criteria were age $\geq 80$ years and history of the disease with no data on cancer.

There were no significant differences in ABO blood types between females and males in the blood donors and oldest-old control groups, so the pooled group was used.

The phenotypes of $\mathrm{ABO}$ blood groups were identified using the seraclones anti-A, B (Bio-Rad Medical Diagnostics $\mathrm{GmbH}$, Dreieich, Germany) antibodies.

Statistical analysis. Statistical analysis was performed using the SPSS 21.0 (IBM Corp., Armonk, NY, USA) and R project 3.4.0 (cran.r-project.org) software package. Categorical data are expressed as frequencies and percentages. The Chi-square test was used to compare the ABO blood group phenotype frequencies among the studied groups. The normal 
approximation method was used to calculate the odds ratio (OR) with the $95 \%$ confidence interval (CI) to measure the association of $\mathrm{ABO}$ blood group phenotypes with prostate, renal cell and bladder cancer in comparison with blood donors and long-survived in the population. In the study, the OR was used to compare the relative odds of the cancer patients having a different $\mathrm{ABO}$ blood group. The risk of disease as the OR was calculated as follows: $\mathrm{OR}=[(n$ of patients with blood group X X n of control with not blood group $\mathrm{X}) /(\mathrm{n}$ of patients with not blood group $\mathrm{X} x \mathrm{n}$ of patients with blood group $\mathrm{X})$ ].

Also, the OR has been calculated with the aim to find out how the ABO blood groups are associated with the likelihood of reaching the oldest-old age ( $\geq 80$ years) in the cancer patients groups. This was calculated as follows: $\mathrm{OR}=[(n$ of oldest-olds with blood group $\mathrm{X} \times \mathrm{x}$ of control with not blood group $\mathrm{X}) /(n$ of oldest-olds with not blood group $\mathrm{X} \times \mathrm{x}$ of control with blood group $\mathrm{X})]$.

$\mathrm{P}<0.05$ was considered to indicate a statistically significant difference.

Hierarchical clustering was used to evaluate the structure of the ABO blood group system data among the analyzed groups, their mathematical similarities and to form groups (clusters). In order to decide where a cluster should be split and to measure dissimilarity among the study groups the Chord metric was used. Cluster analysis was accomplished using the PAST 3.15 software package (folk.uio.no/ohammer/past/). The literature retrieval was accessed through PubMed (1986-2017) using the terms of $\mathrm{ABO}$, cancer, longevity, including the appropriate Boolean operators $A N D$ and $O R$.

\section{Results}

The ABO blood group frequency and $O R$ in cancer patient groups. The frequency of ABO blood groups in the population (blood donors control group) was as follows: O-38.6\%; A-37.5\%, B-16.2\%, AB-7.6\% (Table I).

The comparison of blood type frequency between prostate cancer and blood donors has shown that the blood group B was significantly more frequent in the prostate cancer group $(\mathrm{P}<0.05)$, and the blood type $\mathrm{B}$ was found to be associated with a significantly increased risk of prostate cancer (OR-1.23, $\mathrm{P}<0.05$; Table I). A comparison of the frequency of ABO blood groups between blood donors and the kidney cancer group revealed no significant difference $(\mathrm{P}>0.05$; Table I). Also, no OR significance of any ABO blood group type in the studied kidney cancer groups in association with the blood donor population was found ( $\mathrm{P}>0.05)$.

The blood group B was found to be significantly more frequent in the pooled group suffering from bladder cancer as compared with the frequency in the control group of blood donors $(\mathrm{P}<0.04)$. The blood group $\mathrm{O}$ frequency was lower in the bladder cancer women group $(\mathrm{P}<0.05)$, and the blood type B was more frequent in the bladder cancer men group $(\mathrm{P}<0.04)$ as compared with the blood donor group (Table I). The blood group $\mathrm{O}$ was found to be significantly decreasing the risk of bladder cancer for females (OR-0.76, P<0.05) as tested in association with the blood donors. A statistically significant risk association of the blood type B in the pooled group of the bladder cancer (OR-1.26, $\mathrm{P}<0.04)$ was found also; the male bladder cancer risk was found to be related with the blood type B (OR-1.27, $\mathrm{P}<0.04)$, and no risk related with the blood type B was determined for the female bladder cancer ( $P>0.05$; Table I) as tested in association with the control group of blood donors.

The ABO blood group frequency and $O R$ in the cancer group as compared with the oldest-old group. A comparison of the oldest-old and blood donor groups has revealed that the blood group A is significantly more frequent in the oldest-old group $(\mathrm{P}<0.05)$. In the control group of blood donors, the blood type $\mathrm{B}$ was more frequent than in the oldest-old group $(\mathrm{P}<0.05)$.

A statistically significant difference in the frequency of blood groups was found by comparing the prostate cancer and the oldest-old groups: The blood type A frequency was significantly lower in the prostate cancer as compared with oldest-old group (37.3 and $45.8 \%$, respectively, $\mathrm{P}<0.04)$. The blood group B was more frequent in the prostate cancer group than in the oldest-old group (19.2 and 10.2\%, $\mathrm{P}<0.006)$. The study of OR between the prostate cancer and the oldest-old groups has shown that the blood type B significantly reduces the oldest-old age likelihood in prostate cancer patients (OR-0.48, $\mathrm{P}<0.006)$, and the A blood group has shown an opposite association (OR-1.42, $\mathrm{P}<0.04$; Table II).

No significant difference in the blood group A frequency was found when comparing the pooled and the men kidney cancer patient groups with the oldest-old group ( $\mathrm{P}>0.05)$. A comparison of the women group suffering from kidney cancer with oldest-old individuals showed that the blood group A frequency was lower in the women kidney cancer group $(\mathrm{P}<0.03)$; also, the blood type $\mathrm{B}$ was more frequent in the pooled $(\mathrm{P}<0.03)$, women $(\mathrm{P}<0.007)$ and men $(\mathrm{P}<0.05)$ kidney cancer groups as compared with its frequency in the oldest-olds. The study of OR between the kidney cancer and oldest-old groups has shown that the blood type B significantly reduces the oldest-old age likelihood in all studied kidney cancer groups: Pooled (OR-0.55, P<0.03), men (OR-0.60, $\mathrm{P}<0.05)$ and women (OR-0.49, $\mathrm{P}<0.009)$, and the A blood group has shown a significant opposite association only for the kidney cancer women group (OR-1.46, $\mathrm{P}<0.03)$. The blood type A frequency was found to be significantly lower in pooled individuals suffering from bladder cancer $(\mathrm{P}<0.05)$ as compared with the oldest-old group; also, in oldest-olds the blood type A was more frequent than in the group of men with bladder cancer $(\mathrm{P}<0.05)$. The blood group $\mathrm{B}$ frequency in the bladder cancer pooled group was significantly higher than in the oldest-old group $(\mathrm{P}<0.004)$. A comparison of the blood $\mathrm{B}$ group frequency in the oldest-old group with the men and women bladder cancer groups revealed a statistically higher frequency of the B blood type in the men $(\mathrm{P}<0.003)$ and women $(\mathrm{P}<0.02)$ bladder cancer groups. The study of OR between the bladder cancer and oldest-old groups has shown that the blood type B significantly reduces the oldest-old age likelihood in bladder cancer patients for the pooled (OR-0.47, $\mathrm{P}<0.005)$, men (OR-0.46, $\mathrm{P}<0.004)$ and women $(\mathrm{OR}-0.49, \mathrm{P}<0.02)$ groups, whereas the A blood group has shown a significant opposite association only for the pooled (OR-1.40, $\mathrm{P}<0.04)$ and men (OR-1.47, $\mathrm{P}<0.03)$ bladder cancer groups (Table II).

The cluster data analysis of the study groups. The clustering analysis of the pooled male and female groups has shown that 
Table I. Frequency of the ABO blood groups and OR with 95\% CI in the study cancer and blood donor groups.

\begin{tabular}{|c|c|c|c|c|c|}
\hline \multirow[b]{2}{*}{ Study groups } & \multirow[b]{2}{*}{$\mathrm{n}$} & \multicolumn{4}{|c|}{ Blood groups, \% (n) [OR $(95 \%$ CI)] } \\
\hline & & $\mathrm{O}$ & A & B & $\mathrm{AB}$ \\
\hline Blood donors & 994 & $38.6(384)$ & $37.5(373)$ & $16.2(161)$ & $7.6(76)$ \\
\hline Prostate cancer & 2,200 & $\begin{array}{c}36.0(792) \\
{[0.89(0.77-1.04)]}\end{array}$ & $\begin{array}{c}37.3(821) \\
{[0.99(0.85-1.16)]}\end{array}$ & $\begin{array}{c}19.2(422) \\
{[1.23(1.01-1.50)]^{\mathrm{a}}}\end{array}$ & $\begin{array}{c}7.5(165) \\
{[0.98(0.74-1.30)]}\end{array}$ \\
\hline \multicolumn{6}{|l|}{ Kidney cancer } \\
\hline Pooled group & 2,650 & $\begin{array}{c}37.4(990) \\
{[0.95(0.82-1.01)]}\end{array}$ & $\begin{array}{c}38.2(1012) \\
{[1.03(0.89-1.20)]}\end{array}$ & $\begin{array}{c}17.2(457) \\
{[1.08(0.89-1.31)]}\end{array}$ & $\begin{array}{c}7.2(191) \\
{[0.94(0.71-1.24)]}\end{array}$ \\
\hline Men & 1,553 & $\begin{array}{c}37.7(586) \\
{[0.96(0.82-1.13)]}\end{array}$ & $\begin{array}{c}39.3(610) \\
{[1.08(0.91-1.27)]}\end{array}$ & $\begin{array}{c}16.2(251) \\
{[1.00(0.80-1.24)]}\end{array}$ & $\begin{array}{c}6.8(106) \\
{[0.89(0.65-1.20)]}\end{array}$ \\
\hline Women & 1,097 & $\begin{array}{c}36.8(404) \\
{[0.93(0.78-1.11)]}\end{array}$ & $\begin{array}{c}36.7(402) \\
{[0.96(0.81-1.15)]}\end{array}$ & $\begin{array}{c}18.8(206) \\
{[1.20(0.95-1.50)]}\end{array}$ & $\begin{array}{c}7.7(85) \\
{[1.02(0.74-1.40)]}\end{array}$ \\
\hline \multicolumn{6}{|l|}{ Bladder cancer } \\
\hline Pooled group & 1,530 & $\begin{array}{c}36.5(559) \\
{[0.92(0.78-1.08)]}\end{array}$ & $\begin{array}{c}37.6(575) \\
{[1.00(0.85-1.18)]}\end{array}$ & $\begin{array}{c}19.5(299) \\
{[1.26(1.02-1.55)]^{\mathrm{a}}}\end{array}$ & $\begin{array}{c}6.4(97) \\
{[0.82(0.60-1.12)]}\end{array}$ \\
\hline Men & 1,201 & $\begin{array}{c}37.7(453) \\
{[0.96(0.81-1.14)]}\end{array}$ & $\begin{array}{c}36.5(438) \\
{[0.96(0.80-1.14)]}\end{array}$ & $\begin{array}{c}19.7(237) \\
{[1.27(1.02-1.59)]^{\mathrm{a}}}\end{array}$ & $\begin{array}{c}6.1(73) \\
{[0.78(0.56-1.09)]}\end{array}$ \\
\hline Women & 329 & $\begin{array}{c}32.2(106) \\
{[0.76(0.58-0.98)]^{\mathrm{a}}}\end{array}$ & $\begin{array}{c}41.6(137) \\
{[1.18(0.92-1.53)]}\end{array}$ & $\begin{array}{c}18.9(62) \\
{[1.20(0.87-1.66)]}\end{array}$ & $\begin{array}{c}7.3(24) \\
{[0.95(0.59-1.53)]}\end{array}$ \\
\hline
\end{tabular}

${ }^{\text {a}} \mathrm{P}<0.05$ vs. the blood donor group. OR, odds ratio; $\mathrm{CI}$, confidence interval.

Table II. Frequency of the ABO blood groups in the oldest-old group and the OR with 95\% CI in the studied cancer groups in association with the oldest-old group.

Blood group, OR (95\% CI)

\begin{tabular}{lcllcc}
\cline { 3 - 5 } Study groups & $\mathrm{n}$ & \multicolumn{1}{c}{$\mathrm{O}$} & \multicolumn{1}{c}{$\mathrm{A}$} & \multicolumn{1}{c}{$\mathrm{B}$} & $\mathrm{AB}$ \\
\hline $\begin{array}{l}\text { Oldest-olds, \% (n) } \\
\text { Prostate cancer }\end{array}$ & 166 & $39.2(65)$ & $45.8(76)$ & $10.2(17)$ & $4.8(8)$ \\
$\begin{array}{l}\text { Kidney cancer } \\
\text { Pooled group }\end{array}$ & 2,200 & $1.14(0.83-1.58)$ & $1.42(1.03-1.95)^{\mathrm{a}}$ & $0.48(0.29-0.80)^{\mathrm{b}}$ & $0.645(0.30-1.29)$ \\
$\begin{array}{c}\text { Bladder cancer } \\
\text { Pooled group }\end{array}$ & 2,650 & $1.08(0.78-1.49)$ & $1.37(1.0-1.87)$ & $0.55(0.33-0.91)^{\mathrm{a}}$ & $0.65(0.32-1.35)$ \\
& 1,530 & $1.12(0.81-1.55)$ & $1.40(1.02-1.94)^{\mathrm{a}}$ & $0.47(0.28-0.79)^{\mathrm{b}}$ & $0.75(0.36-1.57)$
\end{tabular}

${ }^{\mathrm{a}} \mathrm{P}<0.05$ and ${ }^{\mathrm{b}} \mathrm{P}<0.01$ vs. oldest-olds. OR, odds ratio; CI, confidence interval.

there are three main clusters. The first cluster is composed of two smaller clusters: The prostate and bladder cancer groups was the first one, and the kidney cancer and blood donors comprised the second cluster. A separate main cluster was the oldest-old group (Fig. 1).

Fig. 2 represents the structural analysis of the cancer female, control and oldest-old groups where females suffering from kidney cancer formed the first cluster with blood donors, and the second and third main clusters consisted of bladder cancer and oldest-old individuals.

A clustering analysis of cancer male individuals and control groups has shown three main clusters: The first comprised the prostate and bladder groups, the second consisted of kidney cancer and blood donor groups, and the third main cluster contained the oldest-old individuals (Fig. 3).

Clusters of the pooled groups showed a close similarity with clusters formed by gender of the male and female groups (Figs. 1-3).

\section{Discussion}

The ABO blood phenotype frequencies vary in different ethnic/racial groups; they vary globally, where the type $\mathrm{O}$ frequency is most common and approaches $100 \%$ among the indigenous populations of South and Central America; the 
A

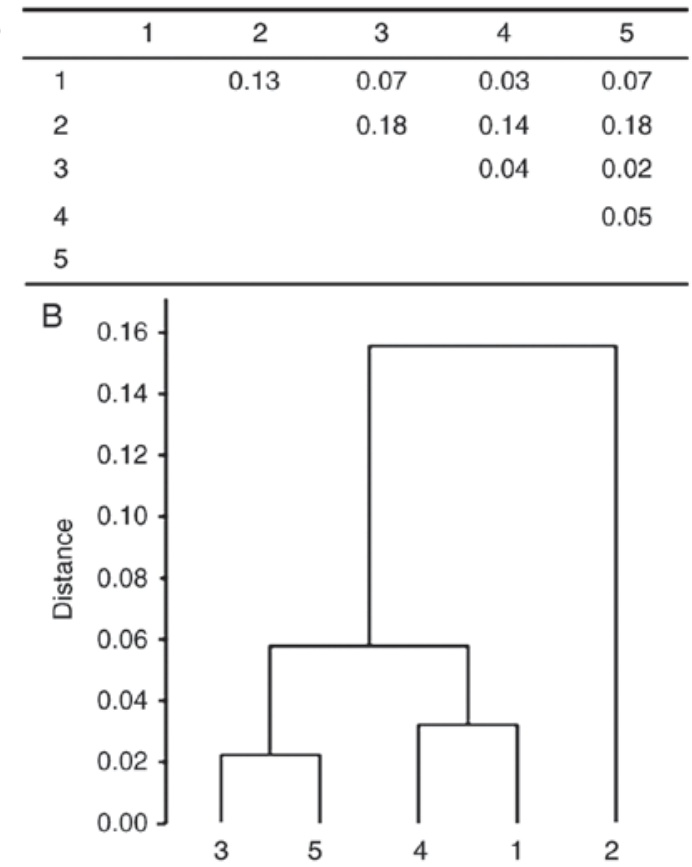

Figure 1. (A) Chord metric distances for pooled study groups. (B) Hierarchica clustering analysis of the pooled study groups. Study groups: 1, blood donors; 2 , oldest-olds; 3 , prostate cancer; 4 , kidney cancer; 5 , bladder cancer.

\begin{tabular}{|c|c|c|c|c|}
\hline & 1 & 2 & 3 & 4 \\
\hline 1 & & 0.13 & 0.06 & 0.14 \\
\hline 2 & & & 0.18 & 0.20 \\
\hline 3 & & & & 0.12 \\
\hline 4 & & & & \\
\hline
\end{tabular}

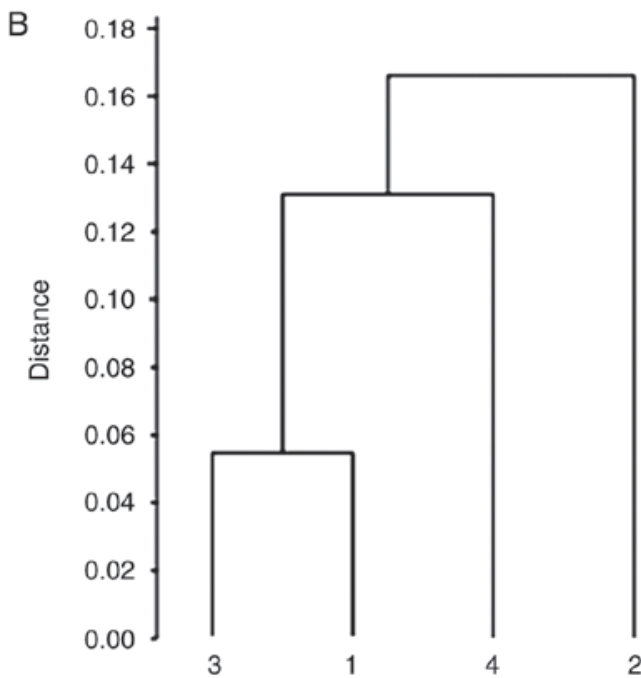

Figure 2. (A) Chord metric distances for female study groups. (B) Hierarchical clustering analysis of the female study groups. Study groups: 1, blood donors; 2 , oldest-olds; 3 , prostate cancer; 4 , kidney cancer.

phenotype A is more common in Eastern and Central Europe, the phenotype $\mathrm{B}$ being more common in China, India and the AB type is more frequent in Korea, China and Japan (32). In the US Caucasians, the frequency of blood groups $\mathrm{O}, \mathrm{A}, \mathrm{B}$ and $\mathrm{AB}$ is $45,40,11$ and $4 \%$, respectively, in Hispanics the distribution

\begin{tabular}{cccccc}
\hline & 1 & 2 & 3 & 4 & 5 \\
\hline 1 & & 0.13 & 0.07 & 0.04 & 0.07 \\
2 & & & 0.18 & 0.11 & 0.18 \\
3 & & & & 0.07 & 0.04 \\
4 & & & & & 0.08 \\
5 & & & & & \\
\hline
\end{tabular}

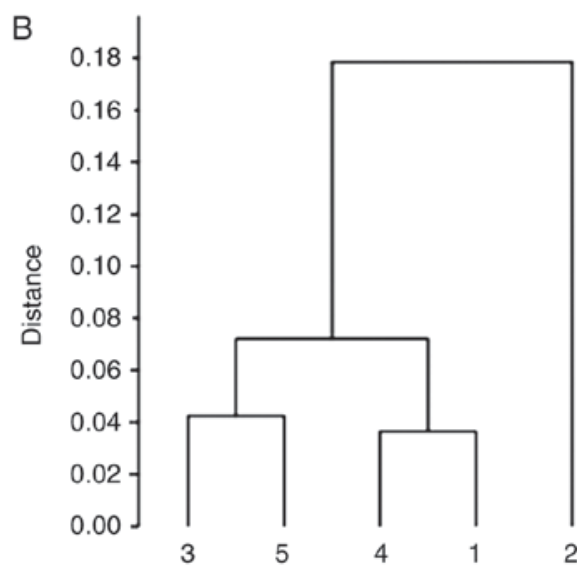

Figure 3. (A) Chord metric distances for male study groups. (B) Hierarchical clustering analysis of the male study groups. Study groups: 1, blood donors; 2, oldest-olds; 3 , prostate cancer; 4 , kidney cancer; 5 , bladder cancer.

being 57, 31, 10 and 3\%; and in Blacks 50, 26, 20 and 4\% (33); in the Lithuanian population, the blood type frequencies (in the blood donors cohort) are as follows: O-38.6\%; A-37.5\%, B-16.2\%, AB-7.6\%. The geographical and ethnic differences in the distribution of ABO blood groups may influence associations between the $\mathrm{ABO}$ blood group phenotypes and the risk of diseases.

The clustering analysis of our studied groups has shown that there are separate main clusters of oldest-old individuals in the analysis of pooled as well as of separate male and female cancer (prostate, bladder, kidney) in comparison with control blood donors and oldest-old groups.

The study data on the ABO blood type frequency and OR in prostate cancer patients (all cases pooled independently of the Gleason score and stage) showed a significantly higher blood group B frequency as compared with the blood donors in the Lithuanian population. Other researchers using three single nucleotide polymorphisms (rs8176746, rs505922, and rs8176704) to determine the ABO genotype in 2,774 aggressive prostate cancer cases (the Gleason score $\geq 8$ or locally advanced/metastatic disease) found no association between the $\mathrm{ABO}$ blood group phenotype and aggressive prostate cancer (34). The lack of association between the ABO blood type and the prostate cancer risk or survival was reported (35). Notably, blood type O prostate cancer patients were at a significantly lower risk of biochemical recurrence as compared with the blood type A patients. The analysis of radical prostatectomy patients and their 5-year biochemical recurrence-free rate showed the blood type $\mathrm{O}$ to be significantly associated with a decreased risk of biochemical recurrence as compared with blood type A patients (36). A significant survival has been reported for prostate cancer blood types $\mathrm{B}$ and $\mathrm{O}$ patients treated with the therapeutic cancer vaccine PROSTVAC-VF, and 
the type B and O PROSTVAC-VF patients demonstrated markedly improved clinical outcomes as compared with the blood types $\mathrm{A}$ and $\mathrm{AB}$ patients, including a longer median survival and the improved overall survival. This indicates that the $\mathrm{ABO}$ blood group may provide a screen to pre-select patients for PROSTVAC-VF therapy (37).

The loss of the blood group A antigen expression in prostate cancer tissue and the retention of the $\mathrm{H}$ antigen (38) as well as the A antigen expression decrease with tumor progression have been reported (39). The lost A antigen expression on cancer cells might be related with the increased risk of biochemical recurrence of prostate cancer in patients with A blood group (36). An alternative explanation of this phenomenon could be the cross-reaction of anti-A antibodies with the tumor-associated $\mathrm{Tn}$ antigen (alpha- $\mathrm{N}$-acetylgalactosamine- $O$-serine/threonine), the latter being expressed in the prostate cancer tissue (40). The Tn antigen is a marker for the design of anti-tumor vaccine studies $(40,41)$. The anti-A antibodies can cross-react with the Tn antigen (42); this cross-reaction might be related with the decreased risk of biochemical recurrence in the blood type $\mathrm{O}$ patients (37). The risk of venous thromboembolic events which are the most common complication and the cause of death within 30 days after radical prostatectomy is greater in patients with a non-O blood phenotype than in those with the $\mathrm{O}$ blood group (43).

Our study of the OR and of the frequency of ABO blood groups shows the bladder cancer risk (in pooled males and females and men bladder cancer groups) to be significantly related with the blood group B, but no such association was determined in Lithuanian cancer female patients; also, the blood group $\mathrm{O}$ was found to be significantly decreasing the risk of bladder cancer for females as tested in association with the blood donors.

The literature data on the $\mathrm{ABO}$ blood group prognostic value in bladder cancer patients are conflicting. Bladder cancer patients with the $\mathrm{O}$ blood type seemed to have a worse clinical outcome than those with non-O blood types. A tendency for high-grade and large-sized tumours was observed in the blood groups $\mathrm{O}$ and B patients (44). A significantly worse 5 -year recurrence-free and cancer-specific survival was associated with a non-O blood type, but no significant difference in the overall survival was found. Non-O blood types were associated with the highest cancer-specific mortality, especially in patients with the blood type A (45). In patients with nonmuscle invasive bladder urothelial carcinoma with blood type $\mathrm{O}$, the recurrence and progression rates were significantly worse than those with blood types A or B (46). In contrast to findings among Europeans and Americans, in the Japan population there were no significant differences among blood groups for the stage, histological grade or survival rate of bladder cancer patients (47). In urothelial bladder carcinoma patients after radical cystectomy, the blood type B was associated with a greater likelihood of lymphovascular invasion and positive soft tissue margins, and blood type B patients showed a significantly higher urothelial bladder carcinoma-related mortality than those with the blood types $\mathrm{O}$ and $\mathrm{AB}$ (48). By other researchers, the $\mathrm{ABO}$ blood group was not associated with the prognosis of bladder cancer patients who underwent radical cystectomy (49).
The cancer originating in epithelial cells and the changes in blood group antigens in the cancer tissue constitute an important aspect in tumor immunology. The expression of soluble A and $\mathrm{B}$ antigens was decreased in patients with bladder cancer in comparison with the normal subjects (50). The reduction of A antigen expression in the bladder cancer tissue was found, while the expression of the A antigen was maintained in the normal or concomitant dysplasia urothelium, indicating that the $\mathrm{ABO}$ gene promoter hypermethylation and/or the gene loss is a specific marker of the bladder cancer (51). The others reported the $\mathrm{ABO}$ blood group antigen expression to be associated with a higher bladder tumor grade, but in adjuvant chemotherapy receiving patients the $\mathrm{AB}$ phenotype antigen expression was associated with a reduced bladder overall and cancer-specific survival (52).

A comparison of the frequency of $\mathrm{ABO}$ blood groups between blood donors and the kidney cancer group revealed no significant difference, and no OR significance of any $A B O$ blood group type in the studied kidney cancer (polled, male and female) groups in association with the blood donors was found in our study. By others, the ABO type frequency differences according to the renal cell carcinoma (RCC) histological subtype (clear cell type and non-clear cell type) reached no statistical significance (32) or the kidney cancer risk was inversely associated with blood type $\mathrm{AB}$ compared with the type O (53). The follow-up cohort study has revealed the RCC incidence to be higher in non-O blood type subjects than in blood type $\mathrm{O}$ women (54).

There are several conflicting reports on the $\mathrm{ABO}$ blood type relationship with the survival of RCC patients. The ABO blood type was reported to be significantly associated with the progression-free survival and cancer-specific survival in patients with RCC following partial or radical nephrectomy: A non-O blood type (A, B or AB) is an independent prognostic factor for a worse progression-free survival outcome, and the blood type $\mathrm{A}$ is an independent factor associated with a worse cancer-specific survival (32). In patients undergoing surgery for loco-regional RCC, the O blood group was found to be independently associated with the better overall survival, and the non-O blood type was identified as an independent predictor of mortality (55). In other studies, the O blood group was associated with the absence or a lower level of lymph node metastases, and this finding did not generate a favourable impact on the RCC prognosis $(56,57)$. Others have reported the ABO blood groups to be not associated with survival outcomes and not a prognostic factor in renal cancer patients after surgery (57). The risk of bilateral RCC was found to be significantly increased in relationship with the $\mathrm{O}$ blood type (56).

ABO antigens may be related with systemic inflammation, and chronic inflammation is associated with RCC (58). The C-reactive protein level was related to the $\mathrm{ABO}$ blood type: RCC patients with the blood type $\mathrm{O}$ had a significantly lower C-reactive protein level than those with a non-O blood type (32). There is a relationship between the $\mathrm{ABO}$ gene and the the tumor necrosis factor alpha (59); the ABO gene locus is linked with TNF- $\alpha$ serum levels (60), so blood group antigens may contribute by modifying the immune surveillance (17). Non-O blood group patients have higher levels of the von Willebrand (vWF) and VIII factors (61). Thus, non-O blood group patients 
have a greater tendency of hypervascularity and hypercoagulability which are typical RCC characteristics. The inquired $\mathrm{A}$ and/or B antigen is lost in the RCC tissue; these structural changes in the $\mathrm{ABH}$ antigen, occuring in the RCC, may enhance the progression of the disease or survival (62-64).

The blood group phenotype $\mathrm{O}$ is characterized by the presence of the $\mathrm{H}$ antigen and the anti-A and anti-B antibodies in the serum (natural isoagglutinins, alloantibodies) which could act as a cancer defense factor $(6,64)$; these isoagglutinins can react to the Tn and T pancarcinoma antigens (65); the A and $\mathrm{B}$ antigens were suggested to be structurally related to $\mathrm{Tn}$ and $\mathrm{T}$ and could make cancer cells immunologically less recognizable in the blood groups A and B individuals (66).

The hypothesis encompasses the enzymatic activity dysregulation of the $\mathrm{ABH}$ glycosyltransferases involved in the processes of cellular adhesion, membrane signaling and immune response $(17,67,68)$. The A/B glycosyltransferases modulate the circulating plasma levels of vWF $(69,70)$; the vWF has been recently found to be an important modulator of angiogenesis and apoptosis which are tumorigenic processes (71). The $\mathrm{A}, \mathrm{B}$ or $\mathrm{H}$ antigens are involved in controlling cell proliferation, adhesion and motility as these antigens are present on receptors for the epidermal growth factor, cadherins, CD44 and integrins (17,72-74). The ABO blood group carbohydrates on the surface of metastatic cancer cells are functioning as cell adhesion molecules (75). There are reports on the association between circulating levels of tumor necrosis factor-alpha and the $A B O$ gene locus polymorphisms (60), the latter being associated with the soluble intercellular adhesion molecule (ICAM-1) (76-78), E-selectin (79,80) and P-selectin (78). All these molecules are immune cell recruitment mediators in chronic inflammation which may have a directly linking ABO blood group and tumor initiation and spread $(81,82)$. Compared with the blood group $\mathrm{O}$, the expression of ICAM-1, which inhibits lymphocyte attachment to endothelial cells, is significantly reduced in patients with a non-O blood group (blood group A in particular) $(6,83)$. The decreased levels of the soluble ICAM in non-O blood group patients may be related to tumor spread (84). This suggestion has been supported with a number of studies showing a decreased survival in non-O blood group and a favorable prognosis in cancer patients with the $\mathrm{O}$ blood group $(85,86)$. With the $\mathrm{A} 1$ allele, the expression of P-selectin and ICAM-1 is associated (78). During inflammation, E-selectin increases leukocyte accumulation, and P-selectin enables leukocytes to interact with endothelial cells or platelets. Inflammatory cytokines rapidly upregulate ICAM-1 and can inhibit lymphocyte adhesion to endothelial cells (83). Compared with non-O blood groups, monocytes of $\mathrm{O}$ blood group individuals produced higher levels of interleukin-6, nitric oxide and tumor necrosis factor-alpha (87).

The $\mathrm{ABH}$ antigens are expressed on the surfaces of several normal and tumour tissues, including the kidneys and renal cell carcinoma lines (17,88), bladder (50-52) and prostate tissue cells $(36,38,39)$. Compared to normal cells, aberrant ABH antigens have been found on tumor tissue cells, such as A or B epitope loss and $\mathrm{H}$ antigen accumulation, or an incompatible expression of tumor $\mathrm{A}$ antigens is notable in blood type $\mathrm{O}$ subjects (17). The loss or diminished expression of $\mathrm{ABH}$ antigens has been reported in both solid and hematological malignancies. There have been occasional case reports of ABO blood group antigen change in malignant conditions, and the antigens were re-expressed when the patients attained remission. There are two possible mechanisms for the weakening of $\mathrm{ABO}$ antigens expression during malignancy: 1) Inactivation of $A$ and $B$ transferases (there is a decreased expression of the $\mathrm{A}$ and $\mathrm{B}$ antigens with a concurrent increase in the $\mathrm{H}$ antigen), 2) the inactivation of $\mathrm{H}$ transferase, related to a decreased $\mathrm{H}$ substance, and a resulting decrease in A and/or B substance (89). An altered expression of ABO antigens may contribute to a malignant phenotype via increased cell motility or enhanced evasion of apoptosis (18). The loss of A or B glycosyltransferase enhances malignancy in human carcinoma cell lines (90) and is associated with a less favorable prognosis (91). In the non-A individuals, tumor cells can express the A antigen, while glycosylation can lead to conformational changes in proteins such as the epidermal growth factor receptor, or alter the immune recognition of natural killer cells which are the conditions favoring tumorigenesis (92). The underlying mechanisms by which the ABO blood group may interplay with tumorigenesis need further research (81). A deletion of A or B antigens in non-O blood group patients leads to the upregulation of the $\mathrm{H}$ precursor and Lewis factor, both of them stimulating neoangiogenesis (93).

In our study, a comparison of the oldest-old and blood donor groups has revealed the blood group A to be significantly more frequent, and the blood type B was significantly rarer in the oldest-old group; the blood type A frequency was significantly lower and the blood group B was significantly more frequent in the prostate cancer group as compared with the oldest-old group, and the study of OR has shown that the blood type B significantly reduces the oldest-old age likelihood in prostate and bladder cancer patients, while the A blood type has shown a significant opposite association in prostate cancer patients.

Our finding that the blood group A was significantly overrepresented in the oldest-old cohort deserves special attention. When comparing cancer patient groups with oldest-olds, the blood group A was found to be significantly overrepresented among urogenital cancer patients. There are two blood group A subtypes, namely A1 and A2, and the A1 allele increases the ABO protein level with the highest enzymatic activity (94). The increased susceptibility of pancreatic cancer has been reported to be possibly connected with the blood group A which is likely to be related with the $A_{1}$ subtype (15). The possible associations with the blood type A have been found in ovarian cancer: Cases with minor alleles of rs1053878 had a $50 \%$ lower risk of death and a better survival related with the blood type A and imply that this relationship may be caused by the A2 allele (95). The meta-analysis of eight studies indicated that women with genetic blood type A variants had a $9 \%$ greater ovarian cancer risk than did blood group $\mathrm{O}$ ones, and the increased risk was only evident for A1 genotype cases (89).

Furthermore, thromboembolism is the additional way by which the ABO blood type may influence the survival of cancer patients. Individuals with the blood type $\mathrm{O}$ are at a lower venous thromboembolism risk and have lower vWF levels than the ones with non-O blood groups, and the A2 blood phenotype was found to be independently related with a lower thromboembolism risk and to have the lowest vWF levels among all other ABO blood phenotypes $(96,97)$. The better survival in relationship with the lower risk of tromboembolism among cancer patients with blood type A could be due to the A2 allele. The limitation of our and many other 
studies of the role of ABO blood groups in longevity is that they do not distinguish between the A1 and A2 subgroups evaluating the phenotype rather than the $\mathrm{ABO}$ genotype, whereas this might be of biological significance as the A1 and A2 glycosyltransferases display different catalytic activities, the $\mathrm{A} 2$ isoform having a higher $\mathrm{K}_{\mathrm{m}}$ and the estimated enzymatic activity 30-50 times lower than A1 (17). The differences in the $\mathrm{A} 1$ and $\mathrm{A} 2$ allelic proportions across different populations may produce some inconsistencies across the studies. A significant increase of the A blood phenotype was observed in the population of healthy elderly males aged over 64 years in the UK (98).

Our OR analysis of the association among cancer and oldest-old groups shows that the blood type B significantly reduces the old-oldest age likelihood in all studied kidney cancer (pooled, men, and women), bladder cancer patients for the pooled and separate men and women groups; notably, the A blood group has shown a significant opposite association for the women kidney cancer, in pooled and men bladder cancer groups in the Lithuanian population. We and others have found a significant association between the blood group B and the higher prevalence of tumors, but there are no clear biological mechanisms to correlate the association of the blood type B with different tumor development (13). The ABO blood type may influence cancer patients' survival by mechanisms related to coagulation. The $\mathrm{ABO}$ gene is responsible for the post-translational glycosylation of the procoagulant molecule vWF (99). Thromboembolism has an impact on the poor cancer patients' survival, and patients with the blood type $\mathrm{O}$ have lower rates of thromboembolism because of the lower levels of vWF and the increased risk for those with blood type B $(100,101)$.

Another study shows a negative relationship between the B blood type and life expectancy in a large cohort $(n=28,129)$; its authors indicate that this evidence may be attributable to the association between the B blood group and some aging-associated conditions raising a new link between the $\mathrm{ABO}$ blood type and cancer (102). Others have found the percentage of patients with the blood group B and their survival to decline with age, and the blood group B may be a marker for earlier death (103). On the contrary, compared to the controls, the B group more frequently was observed in Japanese centenarians, suggesting that the group $\mathrm{B}$ might be associated with longevity; the group B individuals were more likely to survive age-related diseases, since $33 \%$ of the centenarians were free of such diseases, and this did not correlate with the group B. These conflicting results regarding the blood type $\mathrm{B}$ demonstrate that demographic evidences suggest longevity to be possibly caused by different combinations of genes in relation with the different environmental and geographical quantitative and qualitative differences in which the population-specific genetic factors play a role in the longevity (104).

The ABO blood group system is a critical player in the genomic medicine. The structural analysis of our study and other researchers' data indicate the blood type B to be related with the risk of prostate and bladder cancer and could be evaluated as a congenital determinant in the negative relationship with longevity, and that blood types $\mathrm{O}$ and A could be the positive factors increasing the oldest-old age likelihood. Moreover, the further studies of the ABO blood groups evaluating the $A_{1}$ or $A_{2}$ in relationship with the $\mathrm{ABH}$ enzymatic activities, their role in cellular adhesion, immune response in the pathogenesis of cancer could be also important for longevity elucidation.

\section{Acknowledgements}

Not applicable.

\section{Funding}

No funding was received.

\section{Availability of data and materials}

The datasets used and/or analysed during the current study are available from the corresponding author on reasonable request.

\section{Authors' contributions}

DoS, MJ, VL and DŽ were involved in the research area and study design. DoS, AU, DŽ and AS collected patients' data. MJ, AU, DŽ, DoS, DaS, RŠ, AS, KS and VL performed the data analysis. Statistical analysis was conducted by MJ and DoS. All authors contributed important intellectual content during manuscript drafting and revisions, and all accept accountability for the overall work by ensuring that questions pertaining to the accuracy or integrity of any portion of the work are appropriately investigated and resolved. All authors approved the final manuscript version.

\section{Ethics approval and consent to participate}

The present study was approved by the Kaunas Regional Biomedical Research Ethics Committee (Kaunas, Lithuania). Written informed consent was obtained from the patients.

\section{Consent for publication}

Written informed consent was obtained from the patients.

\section{Competing interests}

The authors declare that they have no competing interests.

\section{References}

1. Rummel SK and Ellsworth RE: The role of the histoblood ABO group in cancer. Future Sci OA 2: FSO107, 2016.

2. Stakisaitis D, Lesauskaite V, Girdauskaite M, Janulionis E, Ulys A and Benetis R: Investigation of vitamin D-binding protein polymorphism impact on coronary artery disease and relationship with longevity: Own data and a review. Int $\mathbf{J}$ Endocrinol 2016: 8347379,2016.

3. Clausen $\mathrm{H}$ and Hakomori SI: ABH and related histo-blood group antigens; immunochemical differences in carrier isotypes and their distribution. Vox Sang 56: 1-20, 1989.

4. Dean L: ABO Blood Group. In: Medical genetics summaries [internet]. Pratt V, McLeod H, Dean L, Malheiro A and Rubinstein W (eds). National Center for Biotechnology Information, Bethesda, MD, 2012. https://www.ncbi.nlm.nih. gov/books/NBK100894/. Updated 2015

5. Hamosh A, Scott AF, Amberger J, Bocchini C, Valle D and McKusick VA: Online Mendelian Inheritance in Man (OMIM), a knowledgebase of human genes and genetic disorders. Nucleic Acids Res 30: 52-55, 2002. 
6. Yamamoto F, Cid E, Yamamoto $\mathrm{M}$ and Blancher A: ABO research in the modern era of genomics. Transfus Med Rev 26: 103-118, 2012

7. Mourant AE: Blood relations: Blood groups and anthropology. Oxford University Press, Oxford, pp13-20, 1983.

8. Maynard CL, Elson CO, Hatton RD and Weaver CT: Reciprocal interactions of the intestinal microbiota and immune system. Nature 489: 231-241, 2012

9. de Mattos LC: Structural diversity and biological importance of $\mathrm{ABO}, \mathrm{H}$, Lewis and secretor histo-blood group carbohydrates Rev Bras Hematol Hemoter 38: 331-340, 2016.

10. Aird I, Bentall $\mathrm{HH}$ and Roberts JA: A relationship between cancer of stomach and the ABO blood groups. Br Med J 1: 799-801, 1953

11. Xu YQ, Jiang TW, Cui YH, Zhao YL and Qiu LQ: Prognostic value of $\mathrm{ABO}$ blood group in patients with gastric cancer. J Surg Res 201: 188-195, 2016

12. Amundadottir L, Kraft P, Stolzenberg-Solomon RZ, Fuchs CS, Petersen GM, Arslan AA, Bueno-de-Mesquita HB, Gross M, Helzlsouer K, Jacobs EJ, et al: Genome-wide association study identifies variants in the ABO locus associated with susceptibility to pancreatic cancer. Nat Genet 41: 986-990, 2009.

13. Ben Q, Liu J, Wang W, Guo F, Yao W, Zhong J and Yuan Y: Association between ABO blood types and sporadic pancreatic neuroendocrine tumors in the Chinese Han population. Oncotarget 8: 54799-54808, 2017.

14. Engin H, Bilir C, Üstün $\mathrm{H}$ and Gökmen A: ABO blood group and risk of pancreatic cancer in a Turkish population in Western Black Sea region. Asian Pac J Cancer Prev 13: $131-133,2012$.

15. El Jellas K, Hoem D, Hagen KG, Kalvenes MB, Aziz S, Steine SJ, Immervoll H, Johansson S and Molven A: Associations between $\mathrm{ABO}$ blood groups and pancreatic ductal adenocarcinoma: Influence on resection status and survival. Cancer Med 6: 1531-1540, 2017.

16. Vasan SK, Hwang J, Rostgaard K, Nyrén O, Ullum H Pedersen OBV, Erikstrup C, Melbye M, Hjalgrim H, Pawitan Y and Edgren G: ABO blood group and risk of cancer: A register-based cohort study of 1.6 million blood donors. Cancer Epidemiol 44: 40-43, 2016.

17. Hakomori S: Antigen structure and genetic basis of histo-blood groups $\mathrm{A}, \mathrm{B}$ and $\mathrm{O}$ : Their changes associated with human cancer. Biochim Biophys Acta 1473: 247-266, 1999.

18. Le Pendu J, Marionneau S, Cailleau-Thomas A, Rocher J, Le Moullac-Vaidye B and Clément $\mathrm{M}$ : $\mathrm{ABH}$ and Lewis histo-blood group antigens in cancer. APMIS 109: 9-31, 2001.

19. Franchini M,Liumbruno GM and Lippi G: The prognostic value of ABO blood group in cancer patients. Blood Transfus 14: 434-440, 2016

20. Freudenberg-Hua Y, Freudenberg J, Vacic V, Abhyankar A, Emde AK, Ben-Avraham D, Barzilai N, Oschwald D, Christen E, Koppel J, et al: Disease variants in genomes of 44 centenarians. Mol Genet Genomic Med 2: 438-450, 2014.

21. Sebastiani P, Riva A, Montano M, Pham P, Torkamani A, Scherba E, Benson G, Milton JN, Baldwin CT, Andersen S, et al: Whole genome sequences of a male and female supercentenarian, ages greater than 114 years. Front Genet 2: 90, 2012.

22. Fortney K, Dobriban E, Garagnani P, Pirazzini C, Monti D, Mari D, Atzmon G, Barzilai N, Franceschi C, Owen AB and Kim SK: Genome-wide scan informed by age-related disease identifies loci for exceptional human longevity. PLoS Genet 11: e1005728, 2015

23. Christensen K, Johnson TE and Vaupel JW: The quest for genetic determinants of human longevity: Challenges and insights. Nat Rev Genet 7: 436-448, 2006.

24. Spitsyn VA and Stakishaĭtis DV: Interrelation of genetic dimorphism of ear wax and the level of apolipoproteins with atherogenesis and longevity in the Lithuanian population. Genetika 29: 334-341, 1993 (In Russian).

25. Stakishaŭtis DV, Ianchauskene SM, Ivashkiavichene LI and Priăksha RA: Atherogenesis and serum levels of apolipoprotein E. Kardiologija 32: 14-16, 1992.

26. Stakisaitis D, Maksvytis A, Benetis R and Viikmaa M: Coronary atherosclerosis and blood groups of ABO system in women (own data and review). Medicina (Kaunas) 38 (Suppl 2): S230-S235 2002.

27. Stini WA: Sex differences in bone loss-an evolutionary perspective on a clinical problem. Coll Antropol 27: 23-46, 2003.

28. Znaor A, Laversanne M and Bray F: Less overdiagnosis of kidney cancer? an age-period-cohort analysis of incidence trends in 16 populations worldwide. Int J Cancer 141: 925-932, 2017.
29. Gondos A, Krilaviciute A, Smailyte G, Ulys A and Brenner $\mathrm{H}$ : Cancer surveillance using registry data: Results and recommendations for the Lithuanian national prostate cancer early detection programme. Eur J Cancer 51: 1630-1637, 2015.

30. Huffman DM, Deelen J, Ye K, Bergman A, Slagboom EP Barzilai N and Atzmon G: Distinguishing between longevity and buffered-deleterious genotypes for exceptional human longevity: The case of the MTP gene. J Gerontol A Biol Sci Med Sci 67: $1153-1160,2012$

31. vB Hjelmborg J, Iachine I, Skytthe A, Vaupel JW, McGue M, Koskenvuo M, Kaprio J, Pedersen NL and Christensen K Genetic influence on human lifespan and longevity. Hum Genet 119: 312-321, 2006.

32. Bodmer W: Genetic characterization of human populations: From ABO to a genetic map of the British people. Genetics 199: 267-279, 2015

33. Garratty G, Glynn SA and McEntire R; Retrovirus Epidemiology Donor Study: ABO and $\mathrm{Rh}(\mathrm{D})$ phenotype frequencies of different racial/ethnic groups in the United States. Transfusion 44: 703-706, 2004.

34. Markt SC, Shui IM, Unger RH, Urun Y, Berg CD, Black A, Brennan P, Bueno-de-Mesquita HB, Gapstur SM, Giovannucci E, et al: ABO blood group alleles and prostate cancer risk: Results from the breast and prostate cancer cohort consortium (BPC3). Prostate 75: 1677-1681, 2015.

35. Kvist E, Krogh J and Hjortberg P: Prognostic variables in patients with prostate cancer: Influence of blood group ABO $(\mathrm{H})$, the Rhesus system, age, differentiation, tumour stage and metastases. Int Urol Nephrol 24: 417-423, 1992

36. Ohno Y, Ohori M, Nakashima J, Okubo H, Satake N, Takizawa I, Hashimoto T, Hamada R, Nakagami Y, Yoshioka K and Tachibana M: Associations between ABO blood groups and biochemical recurrence after radical prostatectomy. Int J Clin Exp Med 8: 2642-2648, 2015

37. Muthana SM, Gulley JL, Hodge JW, Schlom J and Gildersleeve JC: ABO blood type correlates with survival on prostate cancer vaccine therapy. Oncotarget 6: 32244-32256, 2015

38. Abel PD, Marsh C, Henderson D, Leathem A, Powell PH and Williams G: Detection of blood group antigens in frozen sections of prostatic epithelium. Br J Urol 59: 430-435, 1987.

39. Chastonay P, Hurlimann J and Gardiol D: Biological tissue markers in benign and malignant disease of the human prostate. Virchows Arch A Pathol Anat Histopathol 410 221-229, 1986

40. Li Q, Anver MR, Butcher DO and Gildersleeve JC: Resolving conflicting data on expression of the Tn antigen and implications for clinical trials with cancer vaccines. Mol Cancer Ther 8: 971-979, 2009

41. Slovin SF, Ragupathi G, Musselli C, Olkiewicz K, Verbel D, Kuduk SD, Schwarz JB, Sames D, Danishefsky S, Livingston PO and Scher HI: Fully synthetic carbohydrate-based vaccines in biochemically relapsed prostate cancer: Clinical trial results with alpha- $\mathrm{N}$-acetylgalactosamine-O-serine/threonine conjugate vaccine. J Clin Oncol 21: 4292-4298, 2003.

42. Hirohashi S, Clausen H, Yamada T, Shimosato Y and Hakomori S Blood group A cross-reacting epitope defined by monoclonal antibodies NCC-LU-35 and -81 expressed in cancer of blood group $\mathrm{O}$ or $\mathrm{B}$ individuals: Its identification as Tn antigen. Proc Natl Acad Sci USA 82: 7039-7043, 1985.

43. Clyne M: Prostate cancer: Non-O blood type is VTE risk factor after radical prostatectomy. Nat Rev Urol 10: 680, 2013.

44. Raitanen MP and Tammela TL: Relationship between blood groups and tumour grade, number, size, stage, recurrence and survival in patients with transitional cell carcinoma of the bladder. Scand J Urol Nephrol 27: 343-347, 1993.

45. Chang SS: Re: The association of ABO blood type with disease recurrence and mortality among patients with urothelial carcinoma of the bladder undergoing radical cystectomy. J Urol 196: 352, 2016.

46. Klatte T, Xylinas E, Rieken M, Kluth LA, Rouprêt M, Pycha A, Fajkovic H, Seitz C, Karakiewicz PI, Lotan Y, et al: Impact of $\mathrm{ABO}$ blood type on outcomes in patients with primary nonmuscle invasive bladder cancer. J Urol 191: 1238-1243, 2014.

47. Yamada T, Fukui I, Yokokawa M and Oshima H: A study of prognosis and clinicopathology of bladder cancer to blood group type of host patients in Japan. Scand J Urol Nephrol 27: 199-203, 1993.

48. Klatte T, Xylinas E, Rieken M, Rouprêt M, Fajkovic H, Seitz C, Karakiewicz PI, Lotan Y, Babjuk M, de Martino M and Shariat SF: Effect of ABO blood type on mortality in patients with urothelial carcinoma of the bladder treated with radical cystectomy. Urol Oncol 32: 625-630, 2014. 
49. Süer E, Özcan C, Gökçe I, Gülpınar Ö, Göğüş C, Türkölmez K, Baltac $\mathrm{S}$ and Bedük Y: Do blood groups have effect on prognosis of patients undergoing radical cystectomy? Int Urol Nephrol 46: 1521-1526, 2014.

50. Foresto P, Bioindi C, Racca L, Brufman A, Yaber F, Solis E, Provenzal $\mathrm{O}$ and Valverde J: Abnormal glycosylation of soluble $\mathrm{ABH}$ antigens in tumors of the urinary tract. Arch Esp Urol 53: 196-199, 2000 (In Spanish).

51. Chihara Y, Sugano K, Kobayashi A, Kanai Y, Yamamoto H, Nakazono M, Fujimoto H, Kakizoe T, Fujimoto K, Hirohashi S and Hirao Y: Loss of blood group A antigen expression in bladder cancer caused by allelic loss and/or methylation of the ABO gene. Lab Invest 85: 895-907, 2005.

52. Engel O, Soave A, Peine S, Kluth LA, Schmid M, Shariat SF, Dahlem R, Fisch M and Rink M: The impact of the AB0 and the Rhesus blood group system on outcomes in bladder cancer patients treated with radical cystectomy. World J Urol 33: 1769-1776, 2015.

53. Sun W, Wen CP, Lin J, Wen C, Pu X, Huang M, Tsai MK, Tsao CK, Wu X and Chow WH: ABO blood types and cancer risk-a cohort study of 339,432 subjects in Taiwan. Cancer Epidemiol 39: 150-156, 2015.

54. Joh HK, Cho E and Choueiri TK: ABO blood group and risk of renal cell cancer. Cancer Epidemiol 36: 528-532, 2012.

55. Kaffenberger SD, Morgan TM, Stratton KL, Boachie AM, Barocas DA, Chang SS, Cookson MS, Herrell SD, Smith JA and Clark PE: ABO blood group is a predictor of survival in patients undergoing surgery for renal cell carcinoma. BJU Int 110: E641-E646, 2012.

56. de Martino M, Waldert M, Haitel A, Schatzl G, Shariat SF and Klatte T: Evaluation of $\mathrm{ABO}$ blood group as a prognostic marker in renal cell carcinoma (RCC). BJU Int 113: E62-E66, 2014.

57. Lee C, You D, Sohn M, Jeong IG, Song C, Kwon T, Hong B, Hong JH, Ahn H and Kim CS: Prognostic value of ABO blood group in patients with renal cell carcinoma: Single-institution results from a large cohort. J Cancer Res Clin Oncol 141: 1441-1447, 2015.

58. Soyupek S, Tulunay O, Armağan A, Hoscan B and Perk H: Clinical importance of intratumoral and normal renal parenchymal inflammatory cell infiltration in renal cell carcinoma. Scand J Urol Nephrol 41: 387-391, 2007.

59. Harrison ML, Obermueller E, Maisey NR, Hoare S, Edmonds K, Li NF, Chao D, Hall K, Lee C, Timotheadou E, et al: Tumor necrosis factor alpha as a new target for renal cell carcinoma: Two sequential phase II trials of infliximab at standard and high dose. J Clin Oncol 25: 4542-4549, 2007.

60. Melzer D, Perry JR, Hernandez D, Corsi AM, Stevens K, Rafferty I, Lauretani F, Murray A, Gibbs JR, Paolisso G, et al: A genome-wide association study identifies protein quantitative trait loci (pQTLs). PLoS Genet 4: e1000072, 2008.

61. Tirado I, Mateo J, Soria JM, Oliver A, Martínez-Sánchez E, Vallvé C, Borrell M, Urrutia T and Fontcuberta J: The ABO blood group genotype and factor VIII levels as independent risk factors for venous thromboembolism. Thromb Haemost 93: 468-474, 2005.

62. Iodice S, Maisonneuve P, Botteri E, Sandri MT and Lowenfels AB: ABO blood group and cancer. Eur J Cancer 46: 3345-3350, 2010.

63. Cordon-Cardo C, Reuter VE, Finstad CL, Sheinfeld J, Lloyd KO, Fair WR and Melamed MR: Blood group-related antigens in human kidney: Modulation of Lewis determinants in renal cell carcinoma. Cancer Res 49: 212-218, 1989.

64. Reid ME and Mohandas N: Red blood cell blood group antigens: Structure and function. Semin Hematol 41: 93-117, 2004

65. Hofmann BT, Stehr A, Dohrmann T, Güngör C, Herich L, Hiller J, Harder S, Ewald F, Gebauer F, Tachezy M, et al: ABO blood group IgM isoagglutinins interact with tumor-associated $\mathrm{O}$-glycan structures in pancreatic cancer. Clin Cancer Res 20: 6117-6126, 2014

66. Ju T, Otto VI and Cummings RD: The Tn antigen-structural simplicity and biological complexity. Angew Chem Int Ed Engl 50: 1770-1791, 2011.

67. Zhang S, Zhang HS, Cordon-Cardo C, Reuter VE, Singhal AK, Lloyd KO and Livingston PO: Selection of tumor antigens as targets for immune attack using immunohistochemistry: II. Blood group-related antigens. Int J Cancer 73: 50-56, 1997.

68. Hakomori S: Tumor-associated carbohydrate antigens defining tumor malignancy: Basis for development of anti-cancer vaccines. Adv Exp Med Biol 491: 369-402, 2001.

69. Williams SR, Hsu FC, Keene KL, Chen WM, Dzhivhuho G, Rowles JL III, Southerland AM, Furie KL, Rich SS, Worrall BB, et al: Genetic drivers of von Willebrand factor levels in an ischemic stroke population and association with risk for recurrent stroke. Stroke 48: 1444-1450, 2017.
70. Franchini M, Crestani S, Frattini F, Sissa C and Bonfanti C: ABO blood group and von Willebrand factor: Biological implications. Clin Chem Lab Med 52: 1273-1276, 2014.

71. Franchini M, Frattini F, Crestani S, Bonfanti C and Lippiet G: Von Willebrand factor and cancer: A renewed interest. Thromb Res 131: 290-292, 2013

72. Furnari FB, Cloughesy TF, Cavenee WK and Mischel PS: Heterogeneity of epidermal growth factor receptor signalling networks in glioblastoma. Nat Rev Cancer 15: 302-310, 2015.

73. Breier G, Grosser M and Rezaei M: Endothelial cadherins in cancer. Cell Tissue Res 355: 523-527, 2014.

74. Prochazka L, Tesarik R and Turanek J: Regulation of alternative splicing of CD44 in cancer. Cell Signal 26: 2234-2239, 2014.

75. Akhtar K, Mehdi G, Sherwani R and Sofi L: Relationship between various cancers and ABO blood groups-a Northern India experience. Internet J Pathol 13: 1, 2010.

76. Paré G, Chasman DI, Kellogg M, Zee RY, Rifai N, Badola S, Miletich JP and Ridkeret PM: Novel association of ABO histo-blood group antigen with soluble ICAM-1: Results of a genome-wide association study of 6,578 women. PLoS Genet 4: e1000118, 2008.

77. Zhang W, Xu Q, Zhuang Y and Chen Y: Novel association of soluble intercellular adhesion molecule 1 and soluble P-selectin with the ABO blood group in a Chinese population. Exp Ther Med 12: 909-914, 2016.

78. Barbalic M, Dupuis J, Dehghan A, Bis JC, Hoogeveen RC, Schnabel RB, Nambi V, Bretler M, Smith NL, Peters A, et al: Large-scale genomic studies reveal central role of ABO in sP-selectin and sICAM-1 levels. Hum Mol Genet 19: 1863-1872, 2010.

79. Paterson AD, Lopes-Virella MF, Waggott D, Boright AP, Hosseini SM, Carter RE, Shen E, Mirea L, Bharaj B, Sun L, et al: Genome-wide association identifies the ABO blood group as a major locus associated with serum levels of soluble E-selectin. Arterioscler Thromb Vasc Biol 29: 1958-1967, 2009.

80. Qi L, Cornelis MC, Kraft P, Jensen M, van Dam RM, Sun Q, Girman CJ, Laurie CC, Mirel DB, Hunter DJ, et al: Genetic variants in $\mathrm{ABO}$ blood group region, plasma soluble E-selectin levels and risk of type 2 diabetes. Hum Mol Genet 19: 1856-1862, 2010

81. Franchini M, Favaloro EJ, Targher G and Lippi G: ABO blood group, hypercoagulability, and cardiovascular and cancer risk. Crit Rev Clin Lab Sci 49: 137-149, 2012.

82. Grivennikov SI, Greten FR and Karin M: Immunity, inflammation, and cancer. Cell 140: 883-899, 2010.

83. Rieckmann P, Michel U, Albrecht M, Brück W, Wöckel L and Felgenhauer K: Soluble forms of intercellular adhesion molecule-1 (ICAM-1) block lymphocyte attachment to cerebral endothelial cells. J Neuroimmunol 60: 9-15, 1995.

84. Kobayashi H, Boelte KC and Lin PC: Endothelial cell adhesion molecules and cancer progression. Curr Med Chem 14: 377-386, 2007.

85. Rahbari NN, Bork U, Hinz U, Leo A, Kirchberg J, Koch M, Büchler MW and Weitz J: AB0 blood group and prognosis in patients with pancreatic cancer. BMC Cancer 12: 319, 2012.

86. Ko K, Park YH, Jeong CW, Ku JH, Kim HH and Kwak C: Prognostic significance of blood type A in patients with renal cell carcinoma. Urol J 13: 2765-2772, 2016.

87. Alkout AM, Blackwell CC and Weir DM: Increased inflammatory responses of persons of blood group $\mathrm{O}$ to Helicobacter pylori. J Infect Dis 181: 1364-1369, 2000.

88. Breimer ME, Mölne J, Nordén G, Rydberg L, Thiel G and Svalander CT: Blood group A and B antigen expression in human kidneys correlated to A1/A2/B, Lewis, and secretor status. Transplantation 82: 479-485, 2006.

89. Nambiar RK, Narayanan G, Prakash NP and Vijayalakshmi K: Blood group change in acute myeloid leukemia. Proc (Bayl Univ Med Cent) 30: 74-75, 2017.

90. Ichikawa D, Handa K and Hakomori S: Histo-blood group A/B antigen deletion/reduction vs. continuous expression in human tumor cells as correlated with their malignancy. Int J Cancer 76: 284-289, 1998

91. Moldvay J, Scheid P, Wild P, Nabil K, Siat J, Borrelly J, Marie B, Farré G, Labib T, Pottier G, et al: Predictive survival markers in patients with surgically resected non-small cell lung carcinoma. Clin Cancer Res 6: 1125-1134, 2000.

92. Greenwell P: Blood group antigens: Molecules seeking a function? Glycoconj J 14: 159-173, 1997.

93. Halloran MM, Carley WW, Polverini PJ, Haskell CJ, Phan S, Anderson BJ, Woods JM, Campbell PL, Volin MV, Bäcker AE and Koch AE: Ley/H: An endothelial-selective, cytokine-inducible, angiogenic mediator. J Immunol 164: 4868-4877, 2000. 
94. Yamamoto F, McNeill PD and Hakomori S: Human histo-blood group A2 transferase coded by A2 allele, one of the A subtypes, is characterized by a single base deletion in the coding sequence, which results in an additional domain at the carboxyl terminal. Biochem Biophys Res Commun 187: 366-374, 1992.

95. Cozzi GD, Levinson RT, Toole H, Snyder MR, Deng A, Crispens MA, Khabele D and Beeghly-Fadiel A: Blood type, ABO genetic variants, and ovarian cancer survival. PLoS One 12: e0175119, 2017.

96. Trégouët DA, Heath S, Saut N, Biron-Andreani C, Schved JF, Pernod G, Galan P, Drouet L, Zelenika D, Juhan-Vague I, et al: Common susceptibility alleles are unlikely to contribute as strongly as the FV and ABO loci to VTE risk: Results from a GWAS approach. Blood 113: 5298-5303, 2009.

97. Ozel AB, McGee B, Siemieniak D, Jacobi PM, Haberichter SL, Brody LC, Mills JL, Molloy AM, Ginsburg D, Li JZ and Desch KC: Genome-wide studies of von Willebrand factor propeptide identify loci contributing to variation in propeptide levels and von Willebrand factor clearance. J Thromb Haemost 14: 1888-1898, 2016.

98. Murray S: ABO groups and $\mathrm{Rh}$ genotypes in the elderly. Br Med J 2: 1472-1474, 1961.

99. Matsui T, Titani K and Mizuochi T: Structures of the asparagine-linked oligosaccharide chains of human von Willebrand factor. Occurrence of blood group $\mathrm{A}, \mathrm{B}$, and $\mathrm{H}(\mathrm{O})$ structures. J Biol Chem 267: 8723-8731, 1992.
100. Ohira T, Cushman M, Tsai MY, Zhang Y, Heckbert SR, Zakai NA, Rosamond WD and Folsom AR: ABO blood group, other risk factors and incidence of venous thromboembolism: The Longitudinal Investigation of Thromboembolism Etiology (LITE). J Thromb Haemos 5: 1455-1461, 2007.

101. Zhou S and Welsby I: Is ABO blood group truly a risk factor for thrombosis and adverse outcomes? World J Cardiol 6: 985-992, 2014.

102. Mengoli C, Bonfanti C, Rossi C and Franchini M: Blood group distribution and life-expectancy: A single-centre experience. Blood Transfus 13: 313-317, 2015.

103. Brecher ME and Hay SN: ABO blood type and longevity. Am J Clin Pathol 135: 96-98, 2011.

104. Shimizu K, Hirose N, Ebihara Y, Arai Y, Hamamatsu M, Nakazawa S, Masui Y, Inagaki H, Gondo Y, Fujimori J, et al: Blood type B might imply longevity. Exp Gerontol 39: 1563-1565, 2004. 